\title{
SOBRE O PODER POLÍTICO DE PINTURAS-DE-FIGURAS-BONITAS DE KITAGAWA UTAMARO
}

\section{Madalena Natsuko Hashimoto Cordaro}

RESUMO: Kitagawa Utamaro é celebre por seus desenhos de estampas de figurasbonitas, bijinga, especialmente na forma de bustos, ôkubi-e ("pintura de grande pescoço"), seja representadas individualmente ou em grupo. À primeira vista, tais representações não apresentam nenhum conteúdo político e, hoje, são reproduzidas para ornamentar espaços públicos (restaurantes, embaixadas) ou objetos de uso cotidiano (carteiras, lenços, agendas, diários) que busquem representar tipicidades nipônicas. A presente comunicação visa a problematizar tal recepção póstuma, pois, conforme editos xogunais de 1790 e 1796, proibiu-se a publicação de estampas em folhas soltas (ichimai$e$ ) nas quais constassem escritos os nomes das mulheres representadas que não fossem yûjo. As séries de mulheres-bonitas de Utamaro são analisadas do ponto de vista da recepção em sua época e dos recursos visuais utilizados pelo pintor para burlar as proibições xogunais.

ABSTRACT: Kitagawa Utamaro is famous for his beauties prints, bijinga, specially in facial portraits, ôkubi-e ("big neck paintings"), depicted individually or in group. At first sight, this kind of representation do not present any political content and today they are reproduced for ornamental purposes, such as in public spaces (restaurants, embassies) or in everyday objects (wallets, scarves, memos and diaries) that aim to represent Japanese singularities. The present communication aims to question this posthumous reception as, following 1790 and 1796 shogunal edits, the publication of one-page prints which contained the represented women names - if they were not $y \hat{u} j o$ - was prohibited. Utamaro series of beauties are analysed from the point-of-view of his time reception and the visual resources the painter recurred in order to run away from shogunal prohibitions. 
PALAVRAS-CHAVE: ukiyo-e de fins do século XVIII; pinturas-de-figuras-bonitas (biijinga), Kitagawa Utamaro e Tsutaya Jûzaburô; proibições xogunais.

KEYWORDS: end of 17 ce. ukiyo-e; beauties-painting (bijinga); Kitagawa Utamaro and Tsutaya Jûzaburô; shogunal prohibitions.

Iniciemos tecendo, primeiramente, algumas considerações de fundo histórico sobre o século XVIII.

Servindo ao sistema xogunal Tokugawa, Tanuma Okitsugu (1718-1788) dá nome a um período também chamado Tanuma (1751-1786), que foi caracterizado pelas reformas que empreendeu, mas, sobretudo, pela primazia do suborno e da corrupção, tendo havido venda de direitos de monopólios e licenças várias. A violência era frequiente, maior do que no tempo de Tokugawa Yoshimune; os levantes de camponeses, devido a abusos e má-administração, eram reprimidos violentamente, tendo havendo várias insurreições e quebra-quebras (uchi-kowashi) nas cidades dirigidas contra os monopolistas. Devido à má colheita, os anos de 1781-1788 se caracterizam por uma fome notória no país e os levantes de camponeses de 1787 se encontram entre os piores do período. Tanuma obrigou os citadinos a conceder grandes empréstimos (goyô-kin), ou melhor, a "doar" grandes somas ao xogunato, devido às finanças deterioradas, em 1761,1785 e 1786.

Como reação a tal estado de coisas, a Reforma Kansei (1787-1793), que deu nome ao período compreendido entre 1789 a 1800, foi liderada pelo Conselheiro Matsudaira Sadanobu, que tentou restringir a influência dos afluentes comerciantes, dissolveu alguns monopólios criados no período Tanuma, cancelou dívidas dos samurais hatamoto e gokenin, e caracterizou sua administração por uma frugalidade extrema e uma volta irrestrita a uma moralidade confucionista. A partir de 1790 institui-se a censura na editoração, aspecto que nos interessa sobretudo neste estudo.

$\mathrm{Na}$ cidade de Edo, os citadinos se encontram em atividade borbulhante no século XVIII, substituindo o até então predomínio cultural da região de Kamigata (Kyôto e Osaka). Entre eles encontram-se vários pintores, escritores, editores, pensadores livres. Kitagawa Utamaro (1753-1806) é contemporâneo dos mais célebres desenhistas de estampas do Segundo Período Edo: Torii Kiyonaga (1752-1815), Katsukawa Shunshô (1726-1792) e seus discípulos, Utagawa Toyoharu (1735-1814) e sua prolífica descendência de pintores. Utamaro foi, principalmente, contemporâneo da figura enigmática Tôshûsai Sharaku, que esteve em atividade durante apenas 9 meses, também sob a mesma casa editora liderada por Tsutaya Jûzaburô, também escritor.

Tido como discípulo do pintor Toriyama Sekien, que seguia a linhagem Kanô, a exaustiva pesquisa de Soda Koichi ${ }^{1}$, na verdade, mostra Utamaro mais como um serviçal do que propriamente um aprendiz de pintura, que teria sido incorporado a seu serviço por sua mãe, como pagamento de favores prestados (segundo a pesquisa de Soda, a mãe de Utamaro teria sido uma obscura gueixa de uma pequena casa de chá). Em 1788, quando morre o mestre Sekien, Utamaro produz ativamente, passando a servir a Tsutaya

1. Soda Kôichi, Utamaro, Tôkyô, Mainichi Shinbunsha, 1985. 
Jûzaburô (1750-1797) $)^{2}$ e tomando morada nos fundos de sua editora. É sob o selo dessa editora que produz muitos livros ilustrados com poemas kyôka (é célebre também a edição, pela mesma casa editora, do álbum de estampas eróticas Utamakura, "Travesseiro de poemas"). Lembre-se, aqui, que "editor" hanmoto, é a figura que ordena, sugere, supervisiona, e leva a efeito todo o processo de impressão: com efeito, Tsutaya não só é escritor de qualidade como agrupa à sua volta pintores, escritores, poetas, entalhadores de matrizes, impressores, encadernadores, todos trabalhadores de grande valor, sendo sua atividade quase tão ou mais importante do que os produtos que ostenta em sua loja.

O presente trabalho muito se beneficiou da análise de Satô Yasuhiro ${ }^{3}$ para fundamentar as reflexões sobre as estampas de figuras-bonitas (bijinga) de Kitagawa Utamaro, muito apreciadas no Ocidente e, por representativas que se tornaram da beleza feminina, ornamentam espaços públicos relacionados ao Japão.

Ôkubi-e, "pinturas de grande pescoço", referem representações humanas reduzidas a feições e uma parte do busto. Não se sabe quando começaram a se tornar uma forma fixa de representação na arte do oriente, mas a introdução no Japão, no período Kamakura, dá-se através da dinastia Sung da China, sendo os primeiros bustos os que representam os patriarcas do zenbudismo. No ukiyo-e, o aparecimento do busto é tardio: o primeiro exemplo foi obra de Nishimura Masanobu, numa estampa parte de uma série de um calendário ilustrado (egoyomi), havendo também o registro de um busto de ator, em abanicos, de Torii Kiyomasu.

A "pintura de grande pescoço" deveria ser o registro de uma individualidade, especialmente do rosto, no qual os olhos concentram a alma da figura, as mãos expressam a atitude (ação) e, em relação à figura inteira (sugata), que é mais discernível por conter mais índices de posição social (roupas, objetos de fundo, posição do corpo, ações), conteria, no dizer de algumas análises contemporâneas, um "teor psicológico" notável.

Assim, embora as primeiras figuras de corpo inteiro, chamadas Kanbun bijin ("figura-bonita" do período Kanbun), não sejam representações genéricas, pois, na verdade, tratava-se de encomendas a pintores para que representassem yûjo existentes na época, somente o rosto era uma "apreensão visual verdadeira" sendo o corpo, a pose, as mãos e os pés, modelos, iguais em quase todas as pinturas que ainda hoje restam.

Satô, rastreando na história do ukiyo-e representações que mostrassem somente faces, acabou encontrando os guias de reputações (hyôbanki) de cortesãs e atores, impressos desde os anos 1660. Entretanto, de fato, como analisa, as representações são menos significativas, em termos de "apreensão visual verdadeira" do que outros índices presentes: quimonos com emblemas, nomes dos estabelecimentos a que se ligam, suas falas, um poema, uma pose em corpo retorcido, um penteado da última moda.

2. Tsutaya Jûzaburô, cognome utilizado por Kitagawa Kamasa, foi proprietário da casa editora também conhecida como Tsutajû, localizada em Nihon-bashi, Ôtemachô, tendo ele mesmo composto poemas kyôka e escrito obras de ficção do gênero gesaku.

3. Da coleção Nihon no bijutsu, o volume 10, de 1975, tem como tema Utamaro to Sharaku. Tôkyô, Shueisha, 1975. 
É intensa a atividade de Hiraga Gennai (1726-1779), estudioso das coisas holandesas, que encomenda a vários pintores, para servir de objeto de julgamento estético em seus encontros de apreciação e intercâmbio, calendários ilustrados (egoyomi kôkankai). É justamente nesses calendários ilustrados que começam a aparecer desenhos doravante apodados nigao-e, "pintura de rosto semelhante" modo que se tornará paradigma para a representação de rostos, seja de atores, seja de cortesãs. Note-se a ressonância de representações nise-e, "pinturas semelhantes [ao modelo]" que vigoraram durante fins do período Heian e início de Kamakura em representações de patriarcas de religiões e personalidades nobiliárquicas e guerreiras. A série Ehon butai ôgi (Leques Ilustrados de Palcos), de Katsukawa Bunchô e Shunshô, obra de 1770, é composta de 106 figuras de atores inseridos em formatos de leques vendidos como recordações da cidade de Edo, "retomam a composição de rostos em meio a leques de Torii Kiyomasu II, mas discernem feições características e individuais, pois nomes e brasões já não são necessários"4.

Lembra também o pesquisador Satô que também no teatro kabuki estava em voga a técnica mono-mane, "imitação [perfeita] das coisas"

A relação do formato leque com a pintura de bustos (ôkubi-e), então, é extremamente forte, e os rostos de atores foram os primeiros objetos de "apreensão visual verdadeira" ou shajitsu.

O autor Satô relaciona, desta forma, a estampa ukiyo-e e o teatro kabuki. Cabenos referir também o grande movimento de renovação iniciado na região de Kansai, por Maruyama Ôkyo (1733-1795) e seus discípulos agrupados na Avenida Shijô, em Kyôto, cujas representações shajitsu de locais-famosos, flores-e-pássaros e figuras humanas são muito relevantes. Com efeito, também os poetas-pintores (bunjin), embora voltados a uma forte coloração chinesa em sua representação que alia o poema composto em chinês com uma paisagem não raro chinesa no imaginário - ou talvez por isso, pois contemporânea, como Ikeno Taiga -, almejam realizar uma "representação verdadeira" uma "vista verdadeira" de um local, no Japão. Embora riaru, riarizumu (corruptela para o idioma japonês dos termos estrangeiros, real, realism) sejam bastante utilizados nas análises pictóricas ou literárias acerca do período, ater-nos-emos aqui a uma tradução mais literal: "rosto-semelhante" para nigao, "cópia-de-modelo" para shajitsu. Compreendemos, assim, a inadequação do trânsito de um número de termos estéticos ocidentais.

Passando a analisar mais especificamente o gênero foco de nossa análise, trazemos mais uma vez um trecho de Satô:

Bijinga ("pintura de figura-bonita") é um gênero que tem forte consciência de seus critérios especiais e que, em relação à imagem de uma aparência real do modelo, procurava uma segunda aparência, que comunicasse um sentimento prazeroso à maior parte das pessoas. Quer dizer, se uma mulher bela fosse representada como uma mulher bela e a seu lado fosse registrado seu nome, isso já seria suficiente, pois o apreciador poderia, assim, imaginar uma yûjo que viesse de encontro a seu desejo particulars.

4. In op. cit., pp. 24-25.

5. In op. cit., p. 29. 
Se o gênero, assim, por um certo tempo, se manteve no acordo implícito entre representação cifrada e interpretação de seu observador (e comprador), o influxo de novos ventos da China chegou a Utamaro, que tornou as figuras femininas mais individualizadas, mais próximas de um modelo real. Ou, pelo menos, assim parece ter pretendido.

Muitos especialistas em estampas ukiyo-e, no Japão, discutem representações de figuras, principalmente de atores, seja no formato ôkubi-e, "pintura de grande pescoço", seja no ôgao-e, "pintura de grande rosto" reconhecendo deveras os atores e suas representações, tal um álbum de fotografias de família: "aqui Ichikawa Danjûrô tinha tantos anos, usava tal vestuário em tal peça, interpretava tal personagem..." Para apreciadores menos especializados ou menos argutos, entretanto, o "realismo" produzido pelos pintores ukiyo-e é geralmente compreendido como uma forma representativa altamente estilizada, com o predomínio da linha sobre a massa.

São de 1792-1793 os primeiros bustos em estampas policromáticas de Utamaro, editados por Tsutaya Jûzaburô: cinco exemplares dentre as dez da série intitulada Fujin sôgaku juttai (Dez Corpos de Fisionomias de Mulheres) e quatro dentre a série de dez de Fujin-sô juppin (Dez Exemplares de Feições de Mulheres). Luxuosamente impressas, com fundo de mica sobre fundo branco (shiro kira), as estampas já passam a trazer o selo de censura xogunal (aratame shirushi), o selo do editor (hanmoto shirushi), a datação, o título, algum texto. São notáveis a importância que o editor adquire e o controle que o poder exerce.

Ao se analisar o título das séries, vê-se em comum o tema fujin, no caso, sinônimo de bijin, "mulher-bonita", e sôgaku, sô: a "fisionomia"'. Em meados do período Edo, a "ciência" da fisionomia estava em voga e muitos livros eram editados sobre o assunto: a personalidade é expressa fisicamente. Utamaro chega até a assinar as estampas das séries com o codinome Sôkan Utamaro kôga: "desenho pensado por Utamaro, o fisionomista [aquele que vê e analisa conforme aparência e atitude]". Assim, o que se pode concluir é que, à determinada "personalidade" corresponderia uma tal "fisionomia"

Utamaro não explica, entretanto, porque a determinado "caráter" corresponderia uma determinada fisionomia, diferentemente das ocasiões nas quais se explicitava uma imagem: etoki, "explicitação pela imagem/pintura" referem cerimônias realizadas geralmente acompanhadas por instrumentos de cordas (koto) desde fins do período Heian, compondo-se de reuniões com explicações de pinturas principalmente de fundo religioso (como, por exemplo, butsuga, pintura de Buda, e jigoku-e, pintura de infernos).

Entre dois caminhos, o de uma representação idealizada de "mulher-bonita", e o de uma que elegesse uma "mulher-bonita" específica, Utamaro, segundo Satô, trilhou um outro caminho: "o de representar figuras de mulheres bonitas segundo uma forma clássica"

6. Ao procurar hoje em dicionários, mesmo os especializados, veremos que tal termo, sôgaku [sô: aparência, figura, atitude; gaku: estudos], em seu aspecto de ressonância homófona não nos passa despercebida, fazendo-nos crer em trocadilho humorístico tão corrente entre os citadinos: Sôgaku [Sô: dinastia Sung] refere os estudos neo-confucionistas adotados pelo xogunato como forma de legitimizar seu poder. Assim, também os citadinos teriam seu "campo de estudos": o estudo das fisionomias das belas das áreas de prazeres e das casas de chá, iniciando-se pelos belos das áreas de dança e representação kabuki. 
Essa forma clássica contempla o cânone poético: em Kasen koi-no bu (Seção de Poemas Seletos de Amor), também editadas por Tsutaya, nos anos 1793-1794, as estampas mostram representações de mulheres associadas a imagens de poetas do período Heian, substituindo-se o poema waka pelas novas formas do momento, haikai e kyôka, "poema-louco", reinterpretando a retomada dos clássicos que Harunobu tornou célebres. Assim como em Harunobu, e também quase todos os desenhistas de estampa do período, a tradição vem traduzida pelo tempo contemporâneo, nos detalhes de vestuário e seus acessórios, no sentido de suas associações. São significativos os títulos das estampas que compõem tal série:

Mono-omou koi: o amor contemplado em momento de ensimesmamento, a mulher-bonita imersa em reflexões sobre o amor, ou sobre seu amante.

Fukaku shinobu koi: o amor profundamente saudoso, já passado.

Arawaruru koi: o amor que se expressa, que aparece à superfície.

Apreciadíssimo por cantar a beleza feminina, Utamaro, entretanto, não se deixou ofuscar pelo brilho formal das grandes cortesãs das áreas de prazeres, tendo feito, antes, uma apologia das mulheres menos graduadas na hierarquia rígida do sistema das áreas-de-prazeres, mostradas com compaixão. Sua série Hokkoku goshiki zumi (Cinco Cores [Tonalidades de Sumi] do País do Norte) é composta de cinco estampas que representam cinco yûjo de Yoshiwara, localizado no "país do norte" da cidade de Edo, e suas respectivas categorias, contendo apenas o título da série e uma gradação de suas posições.

Com exceção de uma do grau oiran, as outras são de baixa extração: kiri-no musume, "moça de cortar" kashi, "beira de rio" teppô, "revólver"

São representações bijinga que não se pode dizer sejam bijin, o gênero "figurabonita", pois com Utamaro passa-se a se mostrar mulheres que não são exatamente um belo modelo que provocasse prazer. Ao contrário, ao mostrar mulheres de baixa extração, Utamaro, na análise de Satô, pela composição (diagonalidade das figuras, torção de cabeças, ausência de mãos, suavidade curvilínea do vestuário e dos seios) e modos de desenhar (finas linhas de contorno nas mãos e no rosto, linhas grossas no vestuário, tinta sumi com superposição de nikawa) revelam uma "expressão vazia": são mulheres que olham para o nada.

Em 1790, os rígidos regulamentos xogunais quanto à publicação de estampas são claros: as estampas em folhas soltas (ichimai-e) não sofrem restrições se não trouxerem texto; entretanto, se os houvesse, estes deveriam ser submetidas à censura"7 Sendo as palavras as que primeiramente se tornaram foco de censura, o escritor do gênero sharebon Santô Kyôden e seu editor, o nosso já conhecido Tsutaya Jûzaburô, são punidos em 17918; mas, entre 1793 e 1795, novas proibições são decretadas e

7. Kanbun no shuppan hôryo, "regulações para a editação do período Kanbun", apud op. cit., pp. 19-20, no qual se cita trecho de édito xogunal que regulavam publicações e congêneres.

8. A punição para Santô Kyôden foi, conforme era praxe, de ter sido algemado por cinquienta dias, sendo impossibilitado de trabalhar; a de Tsutaya, além disso, consistiu em ter metade de seus bens confiscados. 
abuna-e $e^{9}$ e shunga $a^{10}$ são proibidos. Finalmente, em 1796, as estampas em folhas soltas se tornam motivo de grande censura: os nomes das mulheres, com exceção dos de yûjo, e de seus estabelecimentos, não poderiam ser registrados; nas estampas anteriores à lei, seus nomes deveriam ser apagados ${ }^{11}$. Satô, analisando tal proibição, conclui:

Por um lado, a razão de se proibir o registro dos nomes de mulheres que não fossem yûjo, é que o xogunato considerava indecente, lasciva e vulgar a fama que as mulheres comuns das cidades estavam adquirindo, por serem temas das estampas ukiyo-e $\mathrm{e}^{12}$.

O que exatamente seria inapropriado na "fama" de mulheres comuns? Como mercadorias de venda, as yûjo, profissionais da arte amatória, sim, licenciadas pelo xogunato, poderiam ser glorificadas. São inconvenientes, sim, as de baixa extração, principalmente as ilegais ou não-oficiais, pois começam a surgir em grande número nas cidades, seja na figura ostensiva de gueixa independente, seja na figura disfarçada de "moças-atração/símbolo", kanban musume, das "casas de chá de água", mizu jaya que não eram propriamente de chá, mas casas de diversões também eróticas -, além de incontável número de restaurantes e entretenimentos variados que se agregam às vizinhanças das áreas licenciadas.

Foi assim que Utamaro passa a "disfarçar" os nomes das mulheres - num procedimento similar ao que o teatro kabuki já desenvolvia, yatsushi, no qual o disfarce, o engano, a fantasia eram fundamentais -, inserindo em suas estampas pequenos quadros (koma-e) na parte superior com desenhos cifrados (hanji-e) e palavras ocultas (fuchô): numa estampa da série Kômei bijin rokkasen (Seleção de Seis Poemas de MulheresBonitas Famosas), os desenhos-enigmas mostram um sol da manhã (asahi), um tabuleiro de go ( $g o$, homófono também para go que compõe o primeiro ideograma do estabelecimento Goke) e pelos caídos no chão ( $k e$, homófono para $k e$, casa) e uma flecha ( $y a$, homófono para $y a$, estabelecimento comercial), assim referindo a moça da casa Goke do estabelecimento Asahi-ya. Da mesma série, outro quadrinho contém um desenho de leque e uma flecha (Ôgi-ya), uma flor e uma flecha (Hanaôgi): a moça Hanaôgi da casa Ôgi-ya.

Numa outra estampa da série Gonin bijin aikyô kurabe (Comparação de Vitalidades de Cinco Mulheres-Bonitas), vê-se no quadro folhas de pinheiro (matsuba), uma flecha, uma piteira (kiseru, de onde se omitiria a última sílaba) e um rio (kawa): assim é cifrado o nome de Kisegawa do estabelecimento Matsuba-ya.

Finalmente, em 1800, o xogunato passa a proibir o próprio gênero de pinturas de busto. Embora Katsukawa Shunshô, Chôbunsai Eisai e seus discípulos Chôkôsai Eishô e Eiri, além de Chôki, tivessem desenhado para estampas ôkubi-e, foi Utamaro quem mais os produziu. Ironicamente, entretanto, apesar de tantas proibições xogunais, não foi o gênero "figuras-bonitas" o motivo de sua punição em ser algemado, mas um

9. "Pintura-perigosa", refere imagens que mostrem corpos parcialmente desnudos.

10. "Pintura-primavera", refere imagens eróticas, que representem cenas de cópulas.

11. In op. cit., p. 50.

12. In Satô, op. cit., p. 52. 
outro trabalho, para um livro ilustrado, de 1804, uma narrativa de um passado remoto, Ehon Taikô-ki, editado por Moriya Jihei: a estampa que mostra o personagem Taikô, grande guerreiro, como uma forma alusiva ao xôgum reinante, em divertimento com suas cinco esposas, foi considerada ofensiva à classe guerreira.

Sofreram também o mesmo tipo de punição: Katsukawa Shuntei e Shun'ei, Utagawa Toyokuni e Kitagawa Tsukimaro.

Depois de tal humilhação, Utamaro mudou seus temas concentrando-se em alusões classicizantes e representações de usos-e-costumes consoante as atividades do ano, além de maravilhosos álbuns de flores-e-pássaros, numa produção que totaliza, segundo Narazaki Muneshige, 518 obras. Morreu dois anos depois, em 1806 e, como nota Soda, juntamente com muitos outros citadinos prolíficos nas artes da escritura e da pintura que tiveram uma morte precoce.

\section{Bibliografia}

GoTô, Shigemi (org.). Utamaro. In Coleção Ukiyo-e taikei vol. 5. Tôkyô, Shueisha, 1975.

NARAZAKI, Muneshige. Nihon hanga no bi (O Belo da Gravura Japonesa). Tôkyô, Fuji Shobô, 1985.

SATô, Yasuhiro. Utamaro to Sharaku (Utamaro e Sharaku). In Nihon no bijutsu, n. 10, Tôkyô, Shueisha, 1975.

SODA, Kôichi. Utamaro. Tôkyô, Mainichi Shinbunsha, 1985.

SHELDON, Charles David. The rise of the merchand class in Tokugawa Japan, 1600 1868. New York, Association for Asian Studies, 1958. 